\title{
NOTE ON A LEG ABNORMALITY IN ACANTHIA LECTULARIA.
}

\author{
By EDWARD HINDLE, B.A., Ph.D.
}

(From the Quick Laboratory, Cambridge.)

(With 1 Text-figure.)

WHILST engaged in rearing a number of bed-bugs, the variation recorded below was observed in an individual that had just moulted from the first to the second nymphal stage. As such an abnormality does not appear to have been previously described, it seemed worth while to place it on record.

The accompanying figure (Fig. 1) shows that this individual possesses a striking peculiarity in the conformation of its three right legs. On the left side the legs are normally developed and as in most insects are divided into the following segments commencing with the proximal one : coxa, trochanter, femur, tibia, and tarsus. In the adult bug the tarsus is three-jointed, but in the early nymphal stages it is impossible to detect any signs of these segments.

In this example, on the left side the legs are not more than half the size of those on the right and in addition the segmentation is irregular.

In the first leg the femur and tibia seem to be fused together and from the middle of their length arises a bifid protuberance covered with bristles at its two distal extremities. The remaining segments of the limb are of normal aspect but, with the possible exception of the coxa, are incompletely developed.

The second right leg resembles the first, there being no distinct articulation between the femur and tibia, whilst a bifid protuberance arises from what may be regarded as the junction of the two segments. In both cases this protuberance seems to be articulated with the fused femur and tibia, and to constitute a distinct, though incompletely developed, appendage. 
In the third right leg the coxa is normal, and the trochanter, femur and tarsus, although miniature, resemble those of the corresponding

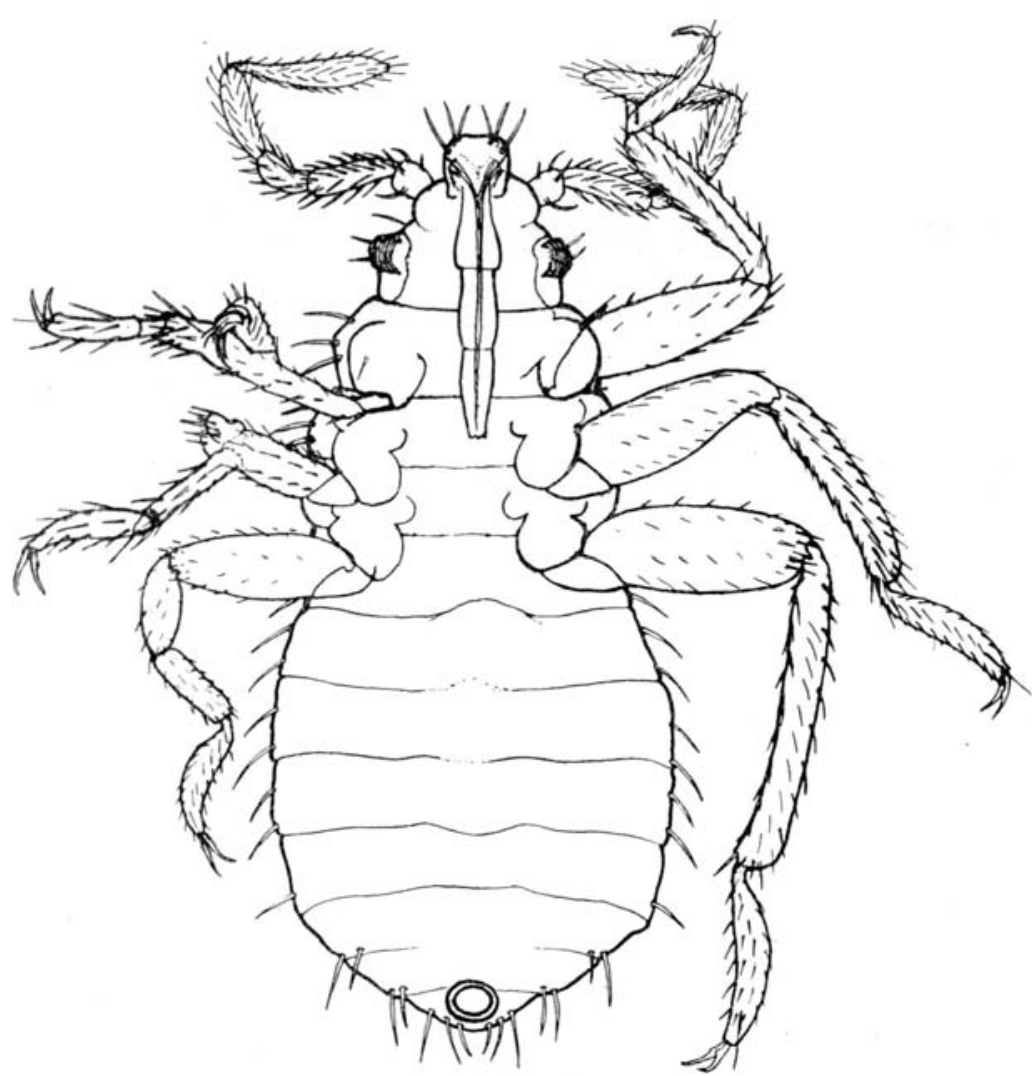

Fig. 1. Acanthia lectularia. Ventral view of abnormal second stage nymph $(\times 60)$.

leg on the opposite side, but the tibia is divided into two segments by an articulation in the middle of its length. There is no trace of the rudimentary appendage present in the first two legs. 